\begin{tabular}{|ccc}
\hline Sournals & $\begin{array}{c}\text { INTERNATIONAL JOURNAL OF } \\
\text { ORGANIZATIONAL LEADERSHIP }\end{array}$ & $\begin{array}{c}\text { INDUSTRIAL } \\
\text { MANAGEMENT } \\
\text { INSTITUTE }\end{array}$ \\
\hline \hline
\end{tabular}

\title{
Drivers of innovative behaviors: The moderator roles of perceived organizational support and psychological empowerment
}

\author{
Bora YILDIZ*, Sümeyra UZUN, Serdar Semih COŞKUN \\ Istanbul University, Faculty of Economics, Department of Business Administration, Beyazit, Istanbul, Turkey
}

\begin{abstract}
Keywords:

Innovative Behaviors,

Perceived Organizational

Support, Proactive

Personality,

Psychological

Empowerment

Received

21 October 2016

Received in revised form

26 May 2017

Accepted

28 May 2017

Correspondence:

borayildiz@istanbul.edu.tr

Innovative behaviors are one of the most important factors that affect the competitive performance of organizations. Although there are numerous studies in the literature which try to determine the antecedents of innovative behaviors, there are still gaps to fully understand the nature of these behaviors. In this respect, the purpose of this study is to determine its individual and organizational-level predictors in the light of the Social Exchange Theory. In this respect, we investigated the effect of proactive personality on innovative behaviors and the moderator roles of perceived organizational support and psychological empowerment on this relationship. More specifically, we hypothesized that employees, who have proactive personality, are more prone to exhibit innovative behaviors. We also hypothesized that the proposed relationship between proactive personality and innovative behaviors is stronger when the levels of perceived organizational support and psychological empowerment is high. The sample of the study consisted of 436 employees (in white goods sector) working in Istanbul. The findings show that proactive personality, perceived organizational support, and psychological empowerment are the statistically significant and positive predictors of innovative behaviors. The most powerful predictor of innovative behaviors in our theoretical model is proactive personality; the others are perceived organizational support and psychological empowerment, respectively. Following this, the findings also show that while the moderating effect of psychological empowerment is statistically significant, the interactional effect of perceived organizational support is not significant. Managerial and further research implications are provided.
\end{abstract}

In today's business world, competition with other organizations is inevitable; even it is essential for sustainable existence. In this respect, to gain competitive advantage, some humanrelated factors come to the forefront of the war; one of these factors is innovative workplace behaviors. To this end, satisfied employees are necessary for organizations to go beyond their formal job specifications (Donavan, Brown, \& Mowen, 2004; Podsakoff, MacKenzie, 
Moorman, \& Fetter, 1990; Williams \& Anderson, 1991). To achieve this, managers or organizations should consider that employees are not one of the expenditure items, instead, they have the reducing effect on all other cost items. Correspondingly, empowerment of employees in the organizations is still one of the important topics in the management field. Although there are plenty of studies in the current literature and they paid attention to enhancing thriving behaviors (Carmeli \& Spreitzer, 2009), there are still gaps to fully understand the nature of these behaviors.

Innovative behaviors are vital for organizations since it is essential for their continuance. These behaviors are the product of individuals' capacity; therefore the level or shape of these behaviors depends on them (Van de Ven, 1986). In this respect giving more attention to their well-being and empowering them will trigger the innovative behaviors. West and Farr (1989) defined innovative behaviors as intentional behaviors that are performance booster. These behaviors contribute to organizations' well-being with the intentional creation, introduction, and application of new ideas within a work role, group or organization (West and Farr, 1989; West, 1989).

In the innovative behaviors literature, there are numerous studies that try to define antecedents and consequences of these behaviors. For instance, Carmeli and Spreitzer (2009), in their model, investigated the effect of trust, connectivity, and thriving (learning and vitality) on innovative behaviors. Similarly, Jansen (2000) explored the effect of job demand on innovative behaviors and the moderator role of perceptions of effort-reward fairness. De Jong and Den Hartog (2007) scrutinized the effect of leadership styles on idea generation and implementation that are stages of the innovative behaviors. Jansen (2003) also investigated the potential effects of innovative behaviors on the co-workers' relations such as conflict with coworkers, job involvement, and satisfaction with co-worker relations. As understood from these studies, while some studies focused on the antecedents of it, the others focused on the consequences. Despite their importance in determining the predictor role of some attitudes, perceptions, and behaviour, the role of employees' psychological empowerment perceptions and organizational support perceptions in the exhibiting innovative workplace behaviors process have not been adequately addressed in the current literature. Hence, the underlying processes through which proactive personality leads to innovative workplace behaviors remain largely unknown.

To fill the gap in research, this study develops a model to explain the concurrent effects of proactive personality on innovative workplace behaviors (Chen, 2011; Seibert, Kraimer, \& Crant, 2001). Based on social exchange theory and organizational support theory we propose that psychologically empowered and supported employees with proactive personality enhanced their attachment to their organizations and then, they could uncover their innovation potential easily. In other words, we argue that perceived organizational support and psychological empowerment moderates the effects of the proactive personality on innovative workplace behaviors.

The present study extends past researches in two ways: First, by incorporating the construct of psychological empowerment, we attempt to explain the link between proactive personality and innovative workplace behaviors using the organizational support perspective. Our study contributes to the innovative workplace behaviors literature by using conditional effect of 
psychological empowerment as a perception. Second, based on social exchange theory, we include perceived organizational support as a moderator in our proposed model. These relationships have been interestingly under-researched in past studies.

The paper proceeds in the following manner. It begins with a literature review on innovative workplace behaviors, proactive personality. Then the moderator roles of perceived organizational support and psychological empowerment in the proactive personalityinnovative workplace behaviors relationship are discussed under the Blau's (1964) social exchange theory. Next, methodology and findings are reported. Lastly, conclusion, limitations, and managerial and further research implications are discussed.

\section{The Literature Review}

Social Exchange Theory (Blau, 1964) suggests that there are interactions among perceptions, attitudes, and behaviors. In other words, the theory suggests that the relationships between individuals are based on some exchanges of sources. From a different viewpoint, the theory refers to a reciprocal doing of a favour. According to this theory, when people have positive perceptions they behave positively as a response to the perceptions. However, if people have negative perceptions, they exhibit negative attitudes or behaviors. On the other hand, Organizational Support Theory (Eisenberger, Huntington, Hutchison, \& Sowa, 1986) is another theory that stresses the importance of organizations' role on the employees' behaviors. perceived organizational support refers to employees "global beliefs concerning the extent to which the organization values their contributions and cares about their well-being" (Eisenberger et al., 1986, p. 501). In this respect, based on social exchange theory and organizational support theory, we propose that if employees with proactive personality perceived organizational support level as high they behave more innovatively than the others. Similarly, if employees perceive themselves as psychologically empowered, their propensity of exhibiting innovative behaviors will be higher.

\section{Innovative Behaviors}

In today's harsh rivalry world, organizations face with many problems in the business environment which are not anticipated earlier. Because of thedynamic work environment, such problems need to be approached by a different perspective when former solutions do not work. These solutions can only come up with by whom that allocate the world distinctive from others and operate procedures to obtain robust outcomes which underpin socio-economic development and welfare in the population (Tierney, Farmer, \& Graen, 1999).

The ability of generating solutions in unexpected situations mostly depends on creative thinking and innovation. Creativity can be defined as producing certain outcomes either products or practical, unique, and useful ideas (Amabile, 1983). In management field, employee creativity is mostly related to individual characteristics such as innovative cognitive style and proactive personality (Chang \& Chen, 2013; Jiang \& Gu, 2015), leadership, work motivation and job satisfaction (Kim \& Lee, 2011), environmental factors within organization e.g. work discretion and time pressure (Chang \& Chen, 2013), and organizational climate (Jafri,Dem, Choden, 2016). According to Oldham and Cummings (1996), employees reveal the 
most creative artifacts when they struggle in complicated jobs provided that they are supported by supervisors during the procedures.

Although creativity and innovation seemto refer to the same meaning, there are slightly different attributes between those concepts. Creativity is generating new ideas without any specific purpose while innovative behavior remains more target-oriented (Abstein, Heidenreich, \&Spieth, 2014). Thus, innovation is a form of creativity that organizations make use for their benefits. Furthermore, unless a genius idea transforms into concrete outcomes such as an implementation, solution or product, it is not an exact but initial part of innovation. Therefore, the innovative behavior is defined as the behavior which stimulates to compose unusual ideas, procedures or products within any organization (Van der Vegt \& Janssen, 2003). Besides, Posthuma, Shih, and Susanto (2011) emphasize that the importance of non-routine tasks which employees occupy within the workplace accelerates. An organization could be able to keep up with today's dynamic business life through innovation. Since nature of non-routine tasks provides development opportunities, these opportunities enhance not only organizational performance (Gao \& Zhang, 2011), but also marketing effectiveness and efficiency (Alpay, Bodur, Yilmaz, \& Büyükbalci, 2012) of organizations.

Scott and Bruce (1994) divide innovation process into three phases. Firstly, an employee realizes a problem and produces proposals for generating a solution. In other words, all aspects of the problem are taken into consideration and a detailed plan illustrating how to achieve goals about the problem is exhibited. Potential of creativity shows up itself in this first stage (McAdam \& McClelland, 2002). Based on a route, several operations are carried out by individuals or teams dealing with the problem in the second stage. This stage overlaps multidimensional constructs that not only individuals but small or large groups can also perform innovative behaviors inside (De Jong \& Den Hartog, 2007). Eventually, all experiences about solutions are generalized for different situations which may emerge soon in both inside or outside of the organization. Therefore, innovative behavior includes initiation, generation, implementation, execution, and realization of ideas (De Jong \& Den Hartog, 2010). Since innovation is a crucial issue in order that organizations and even countries sustain prosperity, there is lots of research investigating which factors trigger innovative behavior in the literature. According to De Spiegelaere, Van Gyes, De Witte, Niesen, \& Van Hootegem, (2014), job insecurity has a negative effect and autonomy has a positive effect on innovative work behavior both directly and indirectly through work engagement. Also, some other factors affecting innovative work behaviors are participative organizational climate (Taştan, 2013), organizational culture (Eskiler,Ekici,Soyer, \& Sari, 2016), and work attitudes including job satisfaction, organizational commitment (Taghipour\&Dezfuli, 2013), job involvement, selfleadership, and proactive personality as a one of the personality traits (Taştan, 2013). Bysted and Hansen (2015) investigated if public sector employees are less innovative than private sector employees. According to the results of their study, there is no meaningful difference between both sectors' workers contrary to popular opinion. Besides, the degree of innovativeness differs from sector to sector. It was also stated that beyond the relationship between employee's positive work attitudes, person-organization fit has also a strong impact on innovative behaviors of employee's through the mediating effect of knowledge sharing behavior (Afsar, 2016). 
Innovative behaviors are vital for organizations. In this respect, determining its predictors is necessary to foster these behaviors. Also, since innovative behavior is considered as a set of cognitional and behavioral structure, it is reasonable to underlie a personality factor as an independent variable within the research model (Taştan, 2013).

\section{Proactive Personality}

Proactive personality can be defined as a kind of personality which reflects the ability to take action to influence environmental change (Kuipers, Higgs,Kickert,Tummers,Grandia,\& Van der Voet, 2014). Outstanding characteristic attributes of proactive personalities that they exhibit consistently are detecting for opportunities, showing initiatives, taking action, and enduring until accomplishing transformation (Bateman \&Crant, 1993; Liao, 2015). People with proactive personality tend to take charges and speak up in society (Morrison \& Phelps, 1999).Besides, they are less open to manipulative effects of environment, whereas nonproactive personalities are more eager to adopt environmental impositions easily (Crant, 2000). In addition, proactive personalities get other people within workplace more durable as themselves against undesirable consequences of stress and anxiety (Yulan, Min, \&Linping, 2014).

In fact, proactive personality is one of the principal indicators of proactive behavior which is defined as "taking the initiative in improving current circumstances or creating new ones; it involves challenging the status quo rather than passively adapting to present conditions" (Crant, 2000). Associated with all concepts that consist of the structure of proactive behavior, it plays a crucial role generally in overall job performance (Chan, 2006; Thompson, 2005). Also, it is drivers of career success (Fuller \&Marler, 2009; Yang \& Chau, 2016) and job satisfaction (Erdogan \& Bauer, 2005). For example, the more CRM agents proactively evaluate feedbacks (VandeWalle\& Cummings, 1997) returning from customers in any business field, the easier they understand what exactly customers need. Then, an employee might have to show personal initiative (Frese, Fay, Hilburger, Leng,Tag, 1997) to fulfill whatever need to be done associated with specialties of business, even though routine patterns order to behave against it. Hence, customer expectations could be accurately satisfied through such proactive behaviors. However, in order to take charge (Morrison \& Phelps, 1999) in such "risky" situation, the employee should obtain role breadth self-efficacy (Parker, Williams, \& Turner, 2006) characteristics. These sort of characteristics may bring the employee to promote and gain competence advantages in an organization against rivals. On the other hand, proactive behaviors are shaped in a context which includes organizational support and leadership (Crant\& Bateman, 2000). Without supportive climate, an employee might avoid taking responsibilities. This may keep employee excluded from job involvement. Therefore, it is so important for managers to put anchors to motivate employee towards the goals (Briscoe, Hall, DeMuth, 2006). Accordingly, these employees may need achievement (Thompson, 2005) more than the others.

Many studies in the literature investigated the relationship of proactive personality concept with several variables. For instance, Jiang and $\mathrm{Gu}$ (2015) revealed that proactive personality enhances employee creativity through the mediating effect of felt responsibility. The felt responsibility for change totally mediates the relationship between proactive personality and 
employee creativity. Moreover, Jafri et al. (2016) stated that proactive personality has a positive moderating effect on the relationship between emotional intelligence and creativity. Kim, Hon, \& Lee (2010) also suggest that proactive personality is positively related to employee creativity. In addition, job creativity requirement and supervisor support for creativity have positive moderator impact on the relationship between proactive personality and employee creativity. Yulan et al. (2014) investigated the moderator role of proactive personality on the relationship between role conflict and job-related anxiety with job satisfaction. In case middle managers exhibit more proactive personality traits, role conflict does not affect either job-related anxiety or job satisfaction. However, if the middle managers are less proactive, then role conflict causes lower job satisfaction and higher work-related anxiety. Odoardi (2014) investigated the moderator role of proactive personality in the relationship between problem-solving demand and innovative behavior. Results showed that problem-solving demand predicts innovative behavior stronger when employees have dominant proactive personality traits. Giebels, Reuver,Rispens, \&Ufkes(2016) suggest that task conflict increases the positive relation between proactive personality and innovative employee behavior.

\section{Proactive Personality and Innovative Workplace Behaviors}

Past researches have shown that proactive personality is associated with engagement, information seeking, and optimism that motivate employees to generate new ideas related to job (Crant, 2000; Fugate, Kinicki, \&Ashforth, 2004; Savickas, 1997). Research in the management literature supports a positive relationship between proactive personality and innovation (Chen, 2011; Seibert et al., 2001). Seibert et al. (2001) state that beyond the big five personality traits, there are also some personality traits that used for explaining the variance in the organizational researches such as proactive personality. According to their study, proactive personality is one of the predictors of innovative behaviors. On the other hand, given the stages of innovative behaviors in idea generation stage, knowledge has an important role. Correspondingly, Carmeli and Spreitzer (2009) emphasized that proactivity is associated with learning. Accordingly, Crant (1996) asserted that proactive personality is a significant predictor of entrepreneurial intentions. Kickul and Gundry (2002) also stated that proactive personality is a significant predictor of innovative targeting processes, innovative organizational systems, and innovative boundary supports.

Past researchers explain the potential constructive effects of proactive personality in the workplace with the social capital perspective (Thampson, 2005). Lin (2001) explains social capital as a series of resources placed in a social structure that are accessed and/or mobilized in purposive activities. According to social capital, perspective employees who want to go beyond formal job requirements should easily access to resources, information, support, and wellestablished contacts by using social networks (Thampson, 2005). Also, Bolino, Turnley, Bloodgood(2002) assert that this relationship between social capital and proactive personality is based on the feeling of willingness to help co-workers, group or organization. Based on these explanations we propose that psychologically empowered and supported employees with proactive personality could exhibit innovative behaviors based on social capital perspective. 


\section{Moderator Role of Psychological Empowerment}

Researchers have focused on the psychological empowerment in parallel with grooving competition and change in the business environment, where initiative and innovative employees are required by organizations (Drucker, 1988). Psychological empowerment is a motivational construct that affects employees' initiating and regulating actions towards performing the job well (Spreitzer, 1995; Thomas \&Velthouse, 1990). It is also related to selfefficacy (Conger \&Kanungo, 1988) meaningfulness of the job, and the ability of impact on the environment (Spreitzer, 1995; Thomas \&Velthouse, 1990). Past researchers emphasized that instead of a single component this construct consists of a few components, namely meaning, competence, self-determination, and impact (Thomas \&Velthouse, 1990). They also assert that psychological empowerment represents, in a broader manner, increasing intrinsic task motivation towards one's work role. In Spreitzer's (1995) study, to better understand this construct some key issues are underlined. One of them is that psychological empowerment is a continuous variable. In other words, they could see themselves more or less empowered instead of empowered or not empowered. Secondly, this phenomenon is valid in the workplace setting (Pierce,Grander, Cummings, \& Dunham, 1989). Thirdly, psychological empowerment is not a constant personality trait, instead, it is a kind of perception, therefore, it depends on personal perceptions towards their work environment (Bandura, 1989).

In literature, there are plenty of studies that investigate the determinants or consequences of psychological empowerment (Avolio, Zhu, Koh, \& Bhatia, 2004; Liden, Wayne, \&Sparrowe, 2000; Spreitzer, 1996; Spreitzer, 1995; Zhang \&Bartol, 2010; Zimmerman, 1995; Zimmerman \& Rappaport, 1988). For instance, Pieterse, Van Knippenberg, Schippers,\&Stam(2010) emphasized that leadership styles have a restrictive impact on psychological empowerment by using norms, rules, regulations, and polices. However, this effect is not valid for all types of leadership styles including transactional and transformational leadership styles. On the other hand, Spreitzer (1995) investigated the effect of self-esteem, locus of control, information, and rewards as antecedents of innovative behaviors. The study also investigated the effectiveness and innovative behaviors as some consequences of the psychological empowerment. As Redmond, Mumford,\& Teach (1993) stated intrinsic task motivation is one of the contributing factors of innovative behaviors. In other words, psychologically empowered employees could be more autonomous and self-efficacy level of these employees are higher; therefore, these conditions lead to increasing the potential of impact on work environment, in turn, creativity (Amabile, 1988). Moreover, as the result of the increased self-efficacy level the capacity of exhibiting innovative behaviors could expand (Amabile, 1988; Conger \&Kanungo, 1988; Kanter, 1983; Redmond et al., 1993; Thomas \&Velthouse, 1990). Psychologically empowered employees act independently, facilitate proactive behaviors, and feel competent and make valuable contributions to their job or work environment (Spreitzer, 1995; Thomas \&Velthouse, 1990). In this respect it is easy to say that to make a different, creative, and valuable contribution to work, employees should feel autonomous and should not fear from making changes in the workplace.

As previously mentioned, the link between proactive personality and innovative behaviors has already been explored by the past researches (Seibert et al., 2001; Chen, 2011). Also, psychological empowerment facilitates proactive behaviors (Spreitzer, 1995; Thomas \& 
Velthouse, 1990). Since proactive personality is one of the drivers of innovative behaviors and since psychological empowerment is a psychological state that has a facilitating effect on proactive personality, we argue that the strength of this relationship will depend on the level of psychological empowerment. In other words, we propose that proactive personality is more effective in engendering innovative workplace behaviors under the conditions of high psychological empowerment than under conditions of low psychological empowerment. It follows that;

\section{Moderator Role of Perceived Organizational Support}

The construct of perceived organizational support (POS) is based on Eisenberger and colleagues' a series of studies (Eisenberger et al., 1986; Eisenberger, Armeli, Rexwinkel, Lynch, \& Rhoades, 2001; Eisenberger, Fasolo, \& Davis-LaMastro, 1990; Eisenberger, Stinglhamber, Vandenberghe, Sucharski, \& Rhoades, 2002; Rhoades \& Eisenberger, 2002). POS is defined as employees in an organization form global beliefs regarding the extent to which the organization consider their contribution important and cares about their well-being (Eisenberger et al., 1986). As understood from this definition, employees' perceptions towards their organizations in terms of organizational support has a key role. In other words, POS is important from two aspects. Firstly, in order to mention organizational support, employees should perceive the support from their organizations. Secondly, organizations or management systems should provide a supportive atmosphere in the workplace. Eisenberger et al. (1986) state that if the level of POS is high, the level of employee attachment to their organization will be higher. To put it another way, based on social exchange perspective, employees would behave more than their organization wants as a response to POS.

In the literature, there are numerous studies that examined the potential effects of POS. In Rhoades and Eisenberger's (2002) meta-analytical study they define three set of antecedents, namely fairness, supervisor support, organizational rewards, andfavourable job conditions, and consequences of POS. Similarly, POS is associated with some individual consequences such as job satisfaction and positive mood, and organizational consequences including affective commitment, performance, and lessened withdrawal behavior. On the other hand, Wayne, Shore, and Liden (1997) in their study tried to combine antecedents of leader-member exchange and POS based on conceptual similarities; however, the findings of the study showed that these two constructs have unique antecedents (i.e. developmental experiences, promotions, and organizational tenure). Shore and Wayne (1993) also supported that, based on social exchange perspective, if employees have a feeling that their organizations attach to them they will feel an obligation to behave more than they want. More specifically, their findings show that POS is the most powerful predictor of organizational citizenship behavior in their theoretical model. Moreover, their findings also show that POS is positively associated with the affective commitment. Additionally, Y1ldiz and Y1ld1z (2015), in their theoretical study, propose that perceived organizational support has a moderating effect on the relationship between employees' servant leadership perception and psychological ownership. Also, Alpkan, Bulut,Gunday, Ulusoy, \& Kilic (2010) in their model indicated that individual direct effects of the dimensions of organizational support (OS), management support for idea development, and tolerance for risk-taking were found to exert positive effects on innovative 
performance. Similarly, Yildiz, Erat, Alpkan, Yild1z, \&Sezen(2015) in their moderated mediation model investigated the conditional effect of POS on the relationship between risk taking propensity and innovative constructive deviant workplace (ICDWB) behaviors through network building. Their findings support the notion that there is a positive link between POS and ICDWB. Interestingly, their findings show that ICDWB increases under the condition of the low level of POS.

In light of the above-mentioned explanations, based on social exchange theory, we propose that proactive personality is more effective in engendering innovative workplace behaviors under the conditions of high perceived organizational support than under conditions of low perceived organizational support.

\section{The Study}

The aim of the current study is to determine the conditional predictors of innovative behaviours in the workplaces setting. In this regard, the effect of proactive personality on innovative behaviours and the moderator roles of perceived organizational support and psychological empowerment on this relationship was investigated. The conceptual model (Figure 1)was developed based on theoretical background (Social Exchange Theory and Organizational Support Theory) and robust theoretical rationales.

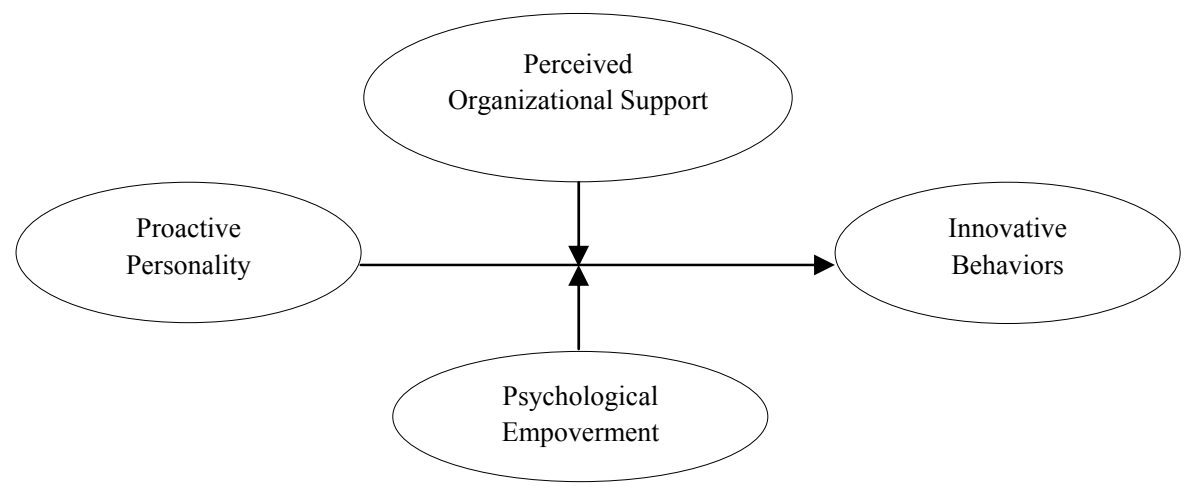

Figure 1. Conceptual model

\section{Research Hypotheses}

The following research hypotheses guided the study.

$\mathbf{H}_{1}$ : Proactive personality positively affects innovative workplace behaviors.

$\mathbf{H}_{2}$ : The relationship between proactive personality and employees' innovative behaviors is moderated by psychological empowerment, such that the relationship is stronger with high psychological empowerment and weaker with low psychological empowerment.

$\mathbf{H}_{3}$ : The relationship between proactive personality and employees' innovative behaviors is moderated by perceived organizational support, such that the relationship is stronger with high perceived organizational support and weaker with low perceived organizational support. 


\section{Method}

Data were collected from 436 workers of white goods sector working in Istanbul, Turkey. Survey method was used for collecting data. In this respect, the data were gathered by hand and face to face interview from participants who were selected via conventional sampling method. Through the process, 500 questionnaires were distributed while 470 were returned. Due to missing information, 34 questionnaires were eliminated;thus, from the sum of responses 34 ( $94 \%$ response rate) were excluded. The majority of the respondents were 31-40 years old (43.3\%), 40.6\% were female, andconsidering the respondents' level of graduation, $48 \%$ were graduated. Following this, $57.6 \%$ were married and they had $1-10$ years of experience $(45.6 \%)$. In this study, innovative behavior was measured with Innovative Behaviors (Scot and Bruce, 1994) 6-item scale. Proactive personality was measured with Proactive Personality (Batteman\&Crant, 1993) 17-item scale. Perceived organizational support was measured with Perceived Organizational Support (Eisenberger, Cunnings, Aemeli, \& Lynch, 1997) 8-item scale. Psychological empowerment was measured with Psychological Empowerment (Avolio et al., 2004) 12-item scale (this scale adapted from 3-item from Jones' (1986) self-efficacy scale, 3-item adapted from Ashforth's (1989) helplessness scale, 3 items were taken from Tymon (1988) meaning scale, and 3-item were taken from Hackman and Oldham's (1980) autonomy scale). All constructs were measured with 5-point response format, ranging from "1 $=$ strongly disagree" and "5 = strongly agree".

\section{Results}

To test the hypotheses, a series of preliminary analysis were used. Firstly, to test the construct validity, exploratory factor analysis was conducted. Furthermore, to test the internal consistency, Cronbach's Alpha test was used (Cronbach, 1951). Then, bivariate correlation analysis was used to test and determine the direction and significance of the relations. Following this, the PROCESS was used to test hypothesized direct and interactional causal effects.

\section{Exploratory Factor Analysis}

In this section, the unidimensional of constructs were tested throughout the principal component analysis (PCA) in exploratory factor analysis (EFA). Furthermore, varimax orthogonal rotation method was applied, so that factor loadings are obtained properly. Initially, there were 15 items in proactive personality scale, but 14 items loaded at the end of the step. Meanwhile, 11 of 12 items in psychological empowerment scale, 8 of 8 items in perceived organizational support scale, and 6 of 11 items in innovative behaviors scale remained at the end of the steps. Therefore, results indicated that factor loadings overlap with former researches as they are represented in the same structure; therefore, it is easy to say that construct validity of all construct are confirmed by the data. Moreover, all these variables in factors explains the $66.88 \%$ (22.77\% of proactive personality, $19.25 \%$ of psychological empowerment, $15.10 \%$ of perceived organizational support, and $9.75 \%$ of innovative behaviors) of total variances as it is shown in Table1. 
Table 1

Factor Analysis Results

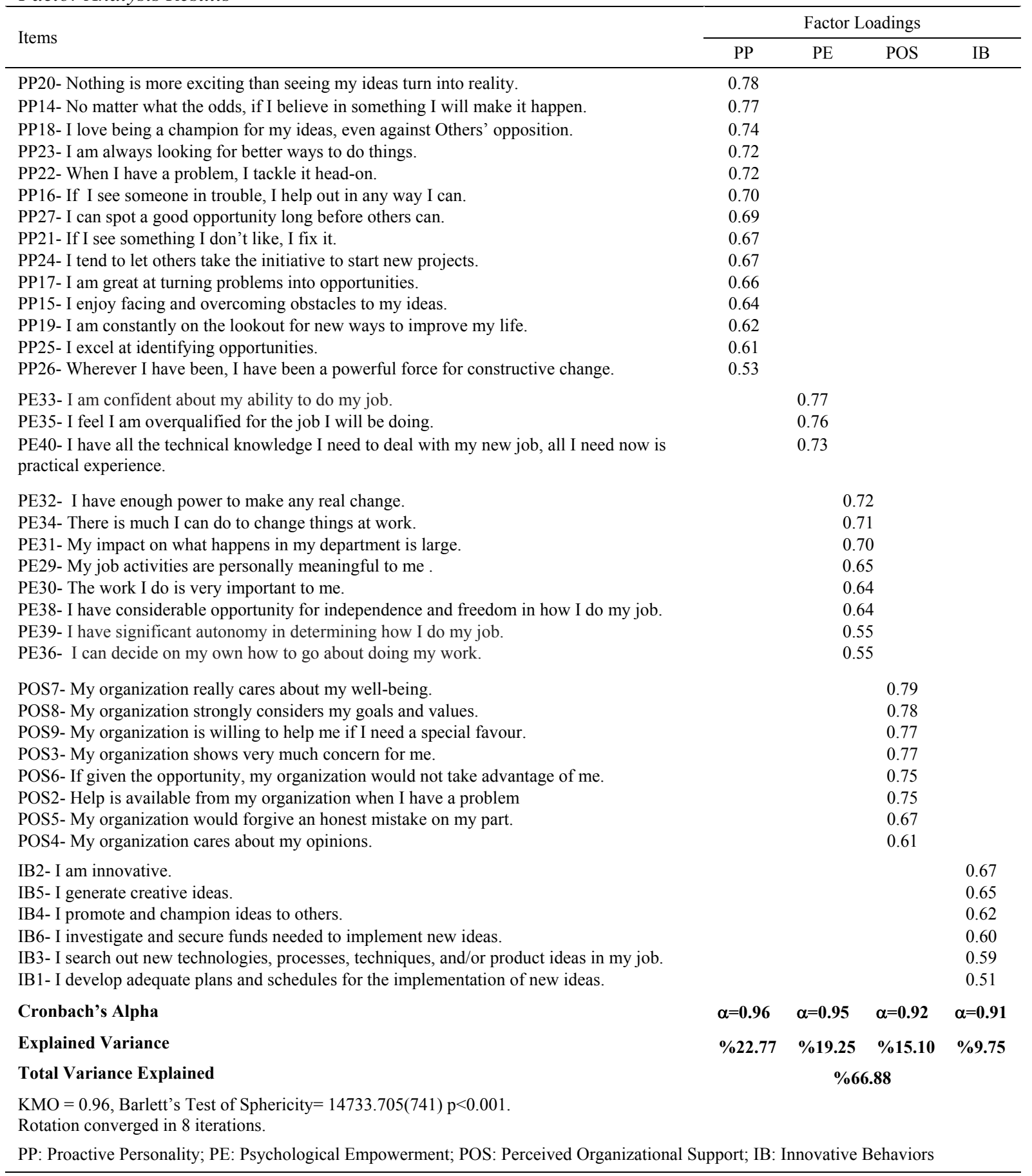

Cronbach's alpha internal consistency scores are $0.96,0.95,0.92$, and 0.91 corresponding to the factors obtained from EFA. These scores are greater enough than the threshold value 0.7 (DeVellis, 2003); therefore, factors are reliable that they are accepted to be used in further analysis.

\section{Common Method Bias}

One of the most crucial problems in terms of data collection is that common method bias may damage the validity of measurements. Since the data is collected from a single source (personal or institutional level) in organizational researches, it may provoke respondents to exibit biassed 
treatments during survey researches (Podsakoff, MacKenzie, Lee, \& Podsakoff, 2003). In order to explore the potential bias factors, Harmon's single factor test was commonly accepted by past studies (Dalton \& Radtke, 2013; Harmon, Brown, Widing, \& Hammond, 2002; Podsakoff \& Organ, 1986). In practise, this test expose all variables' principal component in factor analysis. According to the test results mentioned earlier, the common method bias is not considered statistically significant.

In this study, 4 factors were extracted that their eigenvalues are greater than 1 . All factors together explain $66.88 \%$ of the total variance. As understood from the ratios of each factors $(22.7 \% ; 19.2 \% ; 15.1 \%$; and $9.75 \%$,respectively), there is not a general factor that explains the big partition of the explained totatal variance. Therefore, the problem of common method bias does not exist.

\section{Correlations and Descriptive Statistics}

Descriptive statistics (mean and standard deviation), Cronbach's Alpha reliability scores, and internal correlations coefficients among factors are presented in Table 2.

Table 2

Correlations, Means, Standard Deviations, and Reliability Levels of Variables

\begin{tabular}{lcccccc}
\hline Variable & Mean & S.D. & PP & PE & POS & IB \\
\hline Proactive Personality & 3.70 & 0.79 & $(0.96)$ & & & \\
Psychological Empowerment & 3.58 & 0.82 & $0.78^{* *}$ & $(0.95)$ & & \\
Perceived Organizational Support & 3.78 & 0.78 & $0.50^{* *}$ & $0.53^{* *}$ & $(0.92)$ & \\
Innovative Behaviors & 3.86 & 0.72 & $0.73^{* *}$ & $0.70^{* *}$ & $0.66^{* *}$ & $(0.91)$ \\
\hline
\end{tabular}

According to Table 2, there is a positive and significant relationship between innovative behaviors and proactive personality $(\mathrm{r}=0.73 ; \mathrm{p}<0.01)$; innovative behaviors and psychological empowerment $(\mathrm{r}=0.70 ; \mathrm{p}<0.01)$; innovative behaviors and perceived organizational support $(r=0.66 ; p<0.01)$; perceived organizational support and proactive personality $(r=0.50 ; p<0.01)$; perceived organizational support and psychological empowerment $(\mathrm{r}=0.53 ; \mathrm{p}<0.01)$; and psychological empowerment and proactive personality $(\mathrm{r}=0.78 ; \mathrm{p}<0.01)$.

\section{Direct Effect of Proactive Personality on Innovative Behaviors}

Considering Table 3, all variables have significant effects on innovative behaviors. The regression model is statistically significant $(\mathrm{F}=285.47 ; \mathrm{P}<0.00)$. Additionally, the explanatory power of the model is $66 \%$. Following this, proactive personality is a statistically significant and positive predictor of innovative workplace behaviors $(\beta=392 ; \mathrm{t}=8.63 ; \mathrm{p}<0.00)$. Similarly, Psychological empowerment is a statistically significant and positive predictor of innovative workplace behavior $(\beta=\cdot 20 ; \mathrm{t}=4.33 ; \mathrm{p}<0.00)$. And lastly, perceived organizational support is a statistically significant and positive predictor of innovative workplace behavior $(\beta=\cdot 20$; $\mathrm{t}=4.33 ; \mathrm{p}<0.00$ ). According to these results $9 \mathrm{H}_{1}$ was supported. Table 3 displays all independent variables. 
Table 3

All Independent Variables $\rightarrow$ Innovative Behaviors

\begin{tabular}{ccccccc}
\hline Model & Variables & Std. Coefficients & $\mathrm{t}$ & $\mathrm{p}$ & $\mathrm{D}-\mathrm{W}$ & VIF \\
\hline \multirow{2}{*}{1} & (Constant) & $\beta$ & 5.52 & $0.00^{* * *}$ & & \\
& PP & 0.39 & 8.63 & $0.00^{* * *}$ & 2.03 & 2.65 \\
& PE & 0.20 & 4.33 & $0.00^{* * *}$ & & 2.78 \\
& POS & 0.35 & 10.68 & $0.00^{* * *}$ & & 1.44 \\
\hline
\end{tabular}

Depended Variable: Innovative Behaviors; $R^{2}=0.66, F=285.47 P=0.00 ; * * p<0,01 ; * * * p<0.00$;

Notes: PP: Proactive Personality; PE: Psychological Empowerment; POS: Perceived Organizational Support.

\section{Moderator Role of Psychological Empowerment}

The PROCESS macro within SPSS was used for testing direct and interactional effect (Hayes, 2013). This tool makes complex relations enable to analyzeitems such as moderated mediation, tree-way interaction, and mediated moderation. In addition, it is also conventional to produce more information about some simple moderation or mediation analysis. The result $\mathrm{ofH}_{2}$ is presented in Table 4 .

As it is seen from the model summary (Table 4) $(\mathrm{R}$-square $=0.68 ; \mathrm{F}=200.13 ; \mathrm{p}=0.00$ ) independent variables' (proactive personality and psychological empowerment) power of explanation is enough to explain the variance of dependent variable (innovative behaviours). Also the contribution of moderating effect of psychological empowerment on the direct relationship between proactive personality and innovative behaviours is statistically significant (R-square change $=0.00 ; \mathrm{F}=5.66 ; \mathrm{p}<0.05$ ).

As it is shown in Table 4, proactive personality positively affects innovative behaviors $(\beta=0.04 ; \mathrm{t}=9.64 ; \mathrm{p}<0.00)$ and the psychological empowerment positively affects innovative behaviors $(\beta=0.29 ; \mathrm{t}=6.76 ; \mathrm{p}<0.00)$. Additionally, the moderating effect of psychological empowerment on the relationship between proactive personality and innovative behaviors is significant $(\beta=0.06 ; \mathrm{t}=2.37 ; \mathrm{p}<0.01$ ). Moreover, the three level (low, medium, high) of psychological empowerment positively affects the relationship between proactive personality and innovative behaviors. In other words, it is easy to say that the level of psychological empowerment increases the effects of it on the direct relationship between proactive personality and innovative behaviors, and innovative behaviors also increases. According to these results $\mathrm{H}_{2}$ was supported.

Table 4

Moderating Effect of Psychological Empowerment on the Proactive Personality-Innovative Behaviors Relationship

\begin{tabular}{lcccc}
\hline \multicolumn{5}{c}{ Regression Results for Conditional Effect of Psychological Empowerment } \\
\hline Predictor & $\beta$ & $\mathrm{SE}$ & $\mathrm{t}$ & $\mathrm{p}$ \\
\hline & Innovative Behaviors & & & \\
Constant & 3.82 & 0.02 & 142.13 & $0.00^{* * * *}$ \\
Proactive Personality & 0.44 & 0.04 & 9.64 & $0.00^{* * * *}$ \\
Psychological Empowerment & 0.29 & 0.04 & 6.76 & $0.00^{* * * *}$ \\
Proactive Personality x Psychological Empowerment & 0.06 & 0.02 & 2.37 & 0.01 \\
\hline Psychological Empowerment & Interactional Effect & $\mathrm{SE}$ & $\mathrm{t}$ & $\mathrm{p}$ \\
\hline
\end{tabular}




\begin{tabular}{lcccc}
\hline & \multicolumn{4}{c}{ Conditional Indirect Effect at Psychological Empowerment= M \pm 1 SD } \\
M - 1 SD (-0.82) Low & 0.39 & 0.04 & 8.13 & $0.00^{* * *}$ \\
M (0.00) Medium & 0.44 & 0.04 & 9.64 & $0.00^{* * *}$ \\
M + 1 SD (0.82) High & 0.50 & 0.05 & 9.04 & $0.00^{* * *}$ \\
\hline Model Summary & $\mathrm{R}$ & $\mathrm{R}-\mathrm{sq}$ & $\mathrm{F}$ & $\mathrm{p}$ \\
\hline & 0.76 & 0.58 & 200.13 & $0.00^{* * * *}$ \\
\hline R-sq. Increase due to Interaction & R-sq. change & $\mathrm{F}$ & $\mathrm{df}$ & $\mathrm{p}$ \\
\hline
\end{tabular}

$* * p<0.01 ; * * * * p<0.00$

\section{Moderator Role of Perceived Organizational Support}

As it is seen from the model summary ( $R$-square $=0.65 ; F=269.41 ; p=0.00$ ) independent variables' (proactive personality and perceived organizational support) explanation power is enough to explain the variance of dependent variable (innovative behaviours). However, the contribution of moderating effect of perceived organizational support on the direct relation between proactive personality and innovative behaviours is not statistically significant (Rsquare change $=0.00 ; \mathrm{F}=1.93 ; \mathrm{p}=0.16 \mathrm{~ns}$.)

Additionally, as presented in Table 5, perceived organizational support positively affects innovative behaviors $(\beta=0.35 ; \mathrm{t}=11.47 ; \mathrm{p}<0.00)$. However, the moderator effect of perceived organizational support on the relationship between proactive personality and innovative behaviour is negative and statistically not significant $(\beta=-0.04 ; \mathrm{t}=-1.39 ; \mathrm{p}=0.16 \mathrm{~ns}$.). Moreover, as seen from Table 5, the three-level (low-medium-high) of perceived organizational support negatively affects the direct relationship between proactive personality and innovative behaviors. In other words, when the level of perceived organizational support rises, the effect of direct relationship between proactive personality and innovative behaviours reduces. According to this result, $\mathrm{H}_{3}$ was unsupported.

Table 5

Moderating Effect of Perceived Organizational Support on the Proactive Personality-Innovative Behaviors Relationship

\begin{tabular}{|c|c|c|c|c|}
\hline \multicolumn{5}{|c|}{ Regression Results for Conditional Effect of Perceived Organizational Support } \\
\hline Predictor & $\beta$ & SE & $\mathrm{t}$ & $\mathrm{p}$ \\
\hline \multicolumn{5}{|c|}{ Innovative Behaviors } \\
\hline Constant & 3.87 & 0.02 & 172.17 & $0.00 * * * *$ \\
\hline Proactive Personality & 0.48 & 0.03 & 16.16 & $0.00 * * * *$ \\
\hline Perceived Organizational Support & 0.35 & 0.03 & 11.47 & $0.00 * * * *$ \\
\hline Proactive Personality x Perceived Organizational Support & -0.04 & 0.02 & -1.39 & $0.16 \mathrm{~ns}$ \\
\hline \multirow[t]{2}{*}{ Perceived Organizational Support } & Interactional Effect & SE & $\mathrm{t}$ & $\mathrm{p}$ \\
\hline & \multicolumn{4}{|c|}{ Conditional Indirect Effect at Perceived Organizational Support $=\mathrm{M} \pm 1 \mathrm{SD}$} \\
\hline $\mathrm{M}-1 \mathrm{SD}(-0.78)$ Low & 0.51 & 0.03 & 13.27 & $0.00 * * * *$ \\
\hline M (0.00) Medium & 0.48 & 0.03 & 16.16 & $0.00 * * * *$ \\
\hline $\mathrm{M}+1 \mathrm{SD}(0.78) \mathrm{High}$ & 0.45 & 0.03 & 12.62 & $0.00 * * * *$ \\
\hline \multirow[t]{2}{*}{ Model Summary } & $\mathrm{R}$ & R-sq & $\mathrm{F}$ & $\mathrm{P}$ \\
\hline & 0.80 & 0.65 & 269.41 & $0.00 * * * *$ \\
\hline \multirow[t]{2}{*}{ R-sq. Increase due to Interaction } & R-sq. change & $\mathrm{F}$ & $\mathrm{df}$ & $\mathrm{p}$ \\
\hline & 0.00 & 1.93 & 432 & $0.16 \mathrm{~ns}$ \\
\hline
\end{tabular}


Notes: ${ }^{* *} \mathrm{p}<0.01 ;{ }^{* * * *} \mathrm{p}<0.00 ;$ ns.: non-significant

Overall results of the hypotheses are presented in Table 6.

Table 6

Ultimate Hypothesis Test Results

\begin{tabular}{ll}
\hline Hypotheses & Result \\
\hline H1: Proactive personality positively affects innovative workplace behaviors. & Supported \\
H2: The relationship between proactive personality and employees' innovative behaviors is moderated by \\
$\begin{array}{l}\text { psychological empowerment, such that the relationship is stronger with high psychological empowerment and } \\
\text { weaker with low psychological empowerment. }\end{array}$ & Supported \\
$\begin{array}{l}\text { H3: The relationship between proactive personality and employees' innovative behaviors is moderated by } \\
\text { perceived organizational support, such that the relationship is stronger with high perceived organizational support }\end{array}$ & Unsupported \\
and weaker with low perceived organizational support.
\end{tabular}

\section{Discussion and Conclusion}

Innovation and innovation-related issues have always been one of the main concerns of organizations. From this point of view, organizations that manage this issue gain competitive advantage compared with the competitors. Although innovation is a broad and complex topic, in literature this construct is classified in terms of unit of analysis such as individual level and organizational level. For instance, a past study tackled this issue by investigating organizations' innovative performance (Alpkan et al., 2010). Similarly, there are also various studies that investigate this construct at the individual level including innovative behaviors (Basu \& Green, 1997; Carmeli \& Spreitzer, 2009; Carmeli, Meitar, \& Weisberg, 2006; Munkenbeck Fragaszy \& Visalberghi, 1990; Vinarski-Peretz \& Carmeli, 2011).

In this study, we investigated the effect of proactive personality on the employees' innovative behaviors, and the moderator roles of psychological empowerment and perceived organizational support on this relationship. Our theoretical model is mainly based on social exchange theory and organizational support theory. After the comprehensive literature review, we tried to determine the effect of perceptual variables (perceived organizational support and psychological ownership) on the personality (proactive personality) and behavior relationship (innovative workplace behaviors).

The findings showed that proactive personality is one of the statistical and positive predictors of innovative behaviors. As previously mentioned, this direct relationship has already been explored by the past researches. In this respect, this finding is consistent with the results of the past studies (Chen, 2011; Seibert, Kraimer, \& Crant, 2001). Also, the findings indicated that one of the major moderator hypotheses that propose psychological empowerment moderates the relationship between proactive personality and innovative behaviors was supported. This finding is consistent with the Blaus' (1964) social exchange theory. This finding is consistent with the past studies (Spreitzer, 1995; Thomas \& Velthouse, 1990). In other words, despite the studies did not investigate the moderating effect of psychological empowerment, based on social exchange perspective, they anticipate the intrinsic motivator effect of psychological empowerment exhibiting innovative behaviors; in this respect, our finding was supported by the earlier studies (Redmond et al., 1993;Amabile, 1983,1988). Interestingly, the other major moderator hypothesis that investigates the moderator role of 
perceived organizational support was unsupported. Although this hypothesis developed based on organizational support theory, and there is a positive relationship between perceived organizational support and innovative behaviors, and proactive personality, the interaction between POS and proactive personality is not statistically significant. Accordingly, H3 was unsupported. Despite this result was unpredicted, it has some similarities with the Y1ldiz et al.'s (2015) study. Their study indicates that as the levels of POS decreases, the level of innovative behaviors exhibited by the employees with risk taking propensity through network building increases. These findings could be explained as employees supported by their organizations may prone to fit the routine task behaviors. In other words, supportive climate of the workplace could prevent innovative intentions. Moreover, organizational barriers such as management style, norms, policies or rules could facilitate intrinsic motivators towards employee's innovative behaviors.

Based on the findings of this study, managers or HRM specialist could use affective psychological empowerment tools to foster innovative behaviors in the workplace. Also, being aware of the importance of proactive personality and psychological empowerment, HRM specialist could use effective personal selection and appraisal operations. Rather, based on the findings, managers or practitioners could promote intrinsic motivators instead of external evaluations or supportive approaches.

The findings of this study should be viewed within the context of its limitations. Firstly, this study is based on cross sectional design. In other words, the results of this study represent a limited time period. Further studies could test our theoretical model by using longitudinal research design. Secondly, the sample of this study consisted of white good sector employees, therefore, further researches could test our theoretical model in different sectors. Thirdly, we included perceptual variables that might be potential moderators of POS and proactive personality relationship. Further studies could include other conditional variables such as attitudes, Big Five personality traits or other organizational level perceptions. Additionally, we gathered data from the self-reported method, therefore, there could be social desirability bias problem. In order to eliminate this problem, further researches could gather data from their supervisors or managers. Lastly, although based on theoretical rationales POS was hypothesized as positive potential moderator of the relationship, the data did not support this hypothesis. Therefore, despite conceptual similarities between psychological empowerment and POS, further studies could develop theoretical models that uncover the affective reasoning behind this result.

\section{References}

Abstein, A., Heidenreich, S., \&Spieth, P. (2014). Innovative work behaviour: The impact of comprehensive HR system perceptions and the role of work-life conflict. Industry \& Innovation, 21(2), 91-116.

Afsar, B. (2016). The impact of person-organization fit on innovative work behavior The mediating effect of knowledge sharing behavior. International Journal of Health Care Quality Assurance, 29(2), 104-122.

Alpay, G., Bodur, M., Yilmaz, C., \&Büyükbalci, P. (2012). How does innovativeness yield superior firm performance? The role of marketing effectiveness. Innovation: Management, Policy, \& Practice, 14(1), 107-128.

Alpkan, L., Bulut, C., Gunday, G., Ulusoy, G., \&Kilic, K. (2010). Organizational support for intrapreneurship and its interaction with human capital to enhance innovative performance. Management Decision, 48(5), 732-755.

Amabile, T. M. (1983). The social psychology of creativity: A componential conceptualization. Journal of Personality \& Social Psychology, 45(2), 357-376. 
Amabile, T. M. (1988). A model of creativity and innovation in organizations. In B. M. Staw\& L. L. Cummings (Eds.), Research in organizational behavior(pp. 123-167). Greenwich, CT: JAI Press.

Ashforth, B. E. (1989). The experience of powerlessness in organizations. Organizational Behavior \& Human Decision Processes, 43(2), 207-242.

Avolio, B. J., Zhu, W., Koh, W., \& Bhatia, P. (2004). Transformational leadership and organizational commitment: Mediating role of psychological empowerment and moderating role of structural distance. Journal of Organizational Behavior, 25(8), 951-968.

Bandura, A. 1989. Human agency in social cognitive theory. American Psychologist, 44, 1175-1184.

Basu, R., \& Green, S. G. (1997). Leader-member exchange and transformational leadership: An empirical examination of innovative behaviors in leader-member dyads. Journal of Applied Social Psychology, 27(6), 477-499.

Bateman, T. S., \&Crant, J. M. (1993). The proactive component of organizational behavior: A measure and correlates. Journal of Organizational Behavior, 14(2), 103-118.

Blau, P. M. (1964). Exchange and power in social life. Piscataway, NJ: Transaction Publishers.

Bolino, M. C., Turnley, W. H., \&Bloodgood, J. M. (2002). Citizenship behavior and the creation of social capital in organizations. Academy of Management Review, 27(4), 505-522.

Briscoe, J. P., Hall, D. T., \&DeMuth, R. L. F. (2006). Protean and boundaryless careers: An empirical exploration. Journal of Vocational Behavior, 69(1), 30-47.

Bysted, R., \& Hansen, J. R. (2015). Comparing public and private sector employees' innovative behaviour: Understanding the role of job and organizational characteristics, job types, and subsectors. Public Management Review, 17(5), 698-717.

Carmeli, A., \&Spreitzer, G. M. (2009). Trust, connectivity, and thriving: Implications for innovative behaviors at work. The Journal of Creative Behavior, 43(3), 169-191.

Carmeli, A., Meitar, R., \& Weisberg, J. (2006). Self-leadership skills and innovative behavior at work. International Journal of Manpower, 27(1), 75-90.

Chan, D. (2006). Interactive effects of situational judgment effectiveness and proactive personality on work perceptions and work outcomes. Journal of Applied Psychology, 91(2), 475-481.

Chang, Y. Y., \& Chen, M. H. (2013). Innovative cognitive style, proactive personality and employee creativity: The moderating effects of work discretion and time pressure. In 2013 Proceedings of PICMET'13: Technology Management in the IT-Driven Services (PICMET) (pp. 1521-1534). IEEE.

Chen, W. J. (2011). Innovation in hotel services: Culture and personality. International Journal of Hospitality Management, $30(1), 64-72$.

Conger. J. A., \&Kanungo. R. N. (1988). The empowerment process: integrating theory and practice. Academy of Management Review, 13(3), 471-482.

Crant, J. (2000). Proactive behavior in organizations. Journal of Management, 26(3), 435-462.

Crant, J. M. (1996). The proactive personality scale as a predictor of entrepreneurial intentions. Journal of Small Business Management, 34(3), 42-49.

Crant, J. M., \& Bateman, T. S. (2000). Charismatic leadership viewed from above: the impact of proactive personality. Journal of Organizational Behavior, 21(1), 63-75.

Cronbach, L. J. (1951). Coefficient alpha and the internal structure of tests. Psychometrika, 16(3), 297-334.

Dalton, D., \&Radtke, R. R. (2013). The joint effects of machiavellianism and ethical environment on whistle-blowing. Journal of Business Ethics, 117(1), 153-172.

De Jong, J. P., \& Den Hartog, D. N. (2007). How leaders influence employees' innovative behaviour. European Journal of Innovation Management, 10(1), 41-64.

De Jong, J., \& Den Hartog, D. (2010). Measuring innovative work behaviour. Creativity \& Innovation Management, 19(1), $23-36$

De Spiegelaere, S., Van Gyes, G., De Witte, H., Niesen, W., \& Van Hootegem, G. (2014). On the relation of job insecurity, job autonomy, innovative work behaviour and the mediating effect of work engagement. Creativity \& Innovation Management, 23(3), 318-330

DeVellis, R. F. (2003). Scale development: Theory and applications. Thousand Oaks, Calif: Sage Publications.

Donavan, D. T., Brown, T. J., \&Mowen, J. C. (2004). Internal benefits of service-worker customer orientation: Job satisfaction, commitment, and organizational citizenship behaviors. Journal of Marketing, 68(1), 128-146.

Drucker, P. F. (1988). The coming of the new organization. Harvard Business Review, 66, 45-53. 
Einsenberger, R., Cummings, J., Aemeli, S., \& Lynch, P. (1997). Perceived organizational support, discretionary treatment, and job satisfaction. Journal of Applied Psychology, 82(5), 812-820.

Eisenberger, R., Armeli, S., Rexwinkel, B., Lynch, P. D., \& Rhoades, L. (2001). Reciprocation of perceived organizational support. Journal of Applied Psychology, 86(1), 42-.

Eisenberger, R., Fasolo, P., \& Davis-LaMastro, V. D. (1990). Perceived organizational support and employee diligence, commitment, and innovation. Journal of Applied Psychology, 75(1), 51-59.

Eisenberger, R., Huntington, R., Hutchison, S., \& Sowa, D. (1986). Perceived organizational support. Journal of Applied Psychology, 71, 500-507.

Eisenberger, R., Stinglhamber, F., Vandenberghe, C., Sucharski, I. L., \& Rhoades, L. (2002). Perceived supervisor support: contributions to perceived organizational support and employee retention. Journal of Applied Psychology, 87(3), 565-573.

Erdogan, B., \& Bauer, T. N. (2005). Enhancing career benefits of employee proactive personality: the role of fit with jobs and organizations. Personnel Psychology, 58(4), 859-891.

Eskiler, E., Ekici, S., Soyer, F., \& Sari, I. (2016). The relationship between organizational culture and innovative work behavior for sports services in tourism enterprises. Physical Culture \& Sport Studies \& Research, 69(1), 53-64.

Frese, M., Fay, D., Hilburger, T., Leng, K., \& Tag, A. (1997). The concept of personal initiative: Operationalization, reliability and validity in two German samples. Journal of Occupational \& Organizational Psychology, 70(2), 139-161.

Fugate, M., Kinicki, A. J., \&Ashforth, B. E. (2004). Employability: a psycho-social construct, its dimensions, and applications. Journal of Vocational Behavior, 65(1), 14-38.

Fuller, J. B., \&Marler, L. E. (2009). Change driven by nature: A meta-analytic review of the proactive personality literature. Journal of Vocational Behavior, 75(3), 329-345.

Gao, Q., \& Zhang, C. (2011). Analysis of innovation capability of 125 agricultural high-tech enterprises in China. Innovation, 13(3), 278-290.

Giebels, E., de Reuver, R. S., Rispens, S., \&Ufkes, E. G. (2016). The critical roles of task conflict and job autonomy in the relationship between proactive personalities and innovative employee behavior. The Journal of Applied Behavioral Science, 25(3), 320-341.

Hackman, J. R., \& Oldham, G. R. (1980). Work redesign. Reading, MA: Addison-Wesley.

Harmon, H. A., Brown, G., Widing, R. E., \& Hammond, K. L. (2002). Exploring the sales manager's feedback to a failed sales effort. Journal of Business \& Industrial Marketing, 17(1), 43-55.

Hayes, A. F. (2013). Introduction to mediation, moderation, and conditional process analysis: A regression-based approach. New York, US: The Guilford Press.

Jafri, M. H., Dem, C., \&Choden, S. (2016). Emotional intelligence and employee creativity: Moderating role of proactive personality and organizational climate. Business Perspectives and Research, 4(1), 54-66.

Janssen, O. (2000). Job demands, perceptions of effort-reward fairness and innovative work behaviour. Journal of Occupational and Organizational Psychology, 73(3), 287-302.

Janssen, O. (2003). Innovative behaviour and job involvement at the price of conflict and less satisfactory relations with co-workers. Journal of Occupational \& Organizational Psychology, 76(3), 347-364.

Jiang, W., \&Gu, Q. (2015). A moderated mediation examination of proactive personality on employee creativity: A personenvironment fit perspective. Journal of Organizational Change Management, 28(3), 393-410.

Jones, G. R. (1986). Socialization tactics, self-efficacy and newcomers to organizations. Academy of Management Journal, 29, $262-279$.

Kanter, R. M. (1983). The change masters: Innovations for productivity in the American Cooperation. New York: Simon \& Schuster.

Kickul, J., \& Gundry, L. (2002). Prospecting for strategic advantage: the proactive entrepreneurial personality and small firm innovation. Journal of Small Business Management, 40(2), 85-97.

Kim, J. G., \& Lee, S. Y. (2011). Effects of transformational and transactional leadership on employees' creative behaviour: Mediating effects of work motivation and job satisfaction. Asian Journal of Technology Innovation, 19(2), 233-247.

Kim, T. Y., Hon, A. H., \& Lee, D. R. (2010). Proactive personality and employee creativity: The effects of job creativity requirement and supervisor support for creativity. Creativity Research Journal, 22(1), 37-45.

Kuipers, B. S., Higgs, M., Kickert, W., Tummers, L., Grandia, J., \& Van der Voet, J. (2014). The management of change in public organizations: A literature review. Public Administration, 92(1), 1-20. 
Liao, P. Y. (2015). The role of self-concept in the mechanism linking proactive personality to employee work outcomes. Applied Psychology, 64(2), 421-443.

Liden, R. C., Wayne, S. J., \&Sparrowe, R. T. (2000). An examination of the mediating role of psychological empowerment on the relations between the job, interpersonal relationships, and work outcomes. Journal of Applied Psychology, 85(3), 407416.

Lin, N. (2001). Social capital: A theory of social structure and action. New York: Cambridge University Press.

McAdam, R., \& McClelland, J. (2002). Individual and team-based idea generation within innovation management: Organisational and research agendas. European Journal of Innovation Management, 5(2), 86-97.

Morrison, E. W., \& Phelps, C. C. (1999). Taking charge at work: extrarole efforts to initiate workplace change. Academy of Management Journal, 42(4), 403-419.

MunkenbeckFragaszy, D. M., \&Visalberghi, E. (1990). Social processes affecting the appearance of innovative behaviors in capuchin monkeys. Folia Primatologica, 54, 155-165.

Odoardi, C. (2014). The positive relationship between problem solving demand and innovative work behaviour in the health sector. BPA-Applied Psychology Bulletin (Bollettino di PsicologiaApplicata)62(271), 40-53.

Oldham, G. R., \& Cummings, A. (1996). Employee creativity: Personal and contextual factors at work. Academy of Management Journal, 39(3), 607-634.

Parker, S. K., Williams, H. M., \& Turner, N. (2006). Modeling the antecedents of proactive behavior at work. Journal of Applied Psychology, 91(3), 636-652.

Pierce, L., Gardner. D. G., Cummings, L. L., \& Dunham, R. B. (1989). Organization-based self-esteem: Construct validation, measurement, and validation. Academy of Management Journal, 32, 622-647.

Pieterse, A. N., Van Knippenberg, D., Schippers, M., \&Stam, D. (2010). Transformational and transactional leadership and innovative behavior: The moderating role of psychological empowerment. Journal of Organizational Behavior, 31(4), 609623.

Podsakoff, P. M., \& Organ, D. W. (1986). Self-reports in organizational research: Problems and prospects. Journal of Management, 12(4), 531-544.

Podsakoff, P. M., MacKenzie, S. B., Lee, J.-Y., \&Podsakoff, N. P. (2003). Common method biases in behavioral research: A critical review of the literature and recommended remedies. Journal of Applied Psychology, 88(5), 879-903.

Podsakoff, P. M., MacKenzie, S. B., Moorman, R. H., \& Fetter, R. (1990). Transformational leader behaviors and their effects on followers' trust in leader, satisfaction, and organizational citizenship behaviors. The Leadership Quarterly, 1(2), 107142.

Posthuma, R. A., Shih, H. A., \&Susanto, E. (2011). Is innovative behavior really good for the firm? Innovative work behavior, conflict with coworkers and turnover intention: moderating roles of perceived distributive fairness. International Journal of Conflict Management, 22(2), 111-130.

Redmond, M. R., Mumford, M. D., \& Teach, R. (1993). Putting creativity to work: Effects of leader behavior on subordinate creativity. Organizational Behavior \& Human Decision Processes, 55(1), 120-151.

Rhoades, L., \&Eisenberger, R. (2002). Perceived organizational support: A review of the literature. Journal of Applied Psychology, 87(4), 698-714.

Savickas, M. (1997). Career adaptability: An integrative construct for life-span, life-space theory. Career Development Quarterly, 45(3), 247-259.

Scott, S. G., \& Bruce, R. A. (1994). Determinants of innovative behavior: A path model of individual innovation in the workplace. Academy of Management Journal, 37(3), 580-607.

Seibert, S. E., Kraimer, M. L., \&Crant, J. M. (2001). What do proactive people do? A longitudinal model linking proactive personality and career success. Personnel Psychology, 54(4), 845-874.

Shore, L. M., \& Wayne, S. J. (1993). Commitment and employee behavior: Comparison of affective commitment and continuance commitment with perceived organizational support. Journal of Applied Psychology, 78(5), 774-780.

Spreitzer, G. M. (1995). Psychological empowerment in the workplace: Dimensions, measurement, and validation. Academy of Management Journal, 38(5), 1442-1465.

Spreitzer, G. M. (1996). Social structural characteristics of psychological empowerment. Academy of Management Journal, $39(2), 483-504$

Taghipour, A., \&Dezfuli, Z. K. (2013). Innovative behaviors: Mediate mechanism of job attitudes. Procedia - Social \&Behavioral Sciences, 84, 1617-1621. 
Taştan, S. B. (2013). The influences of participative organizational climate and self-leadership on innovative behavior and the roles of job involvement and proactive personality: A survey in the context of SMEs in İzmir. Procedia - Social \&Behavioral Sciences, 75, 407-419.

Thomas, K. W., \&Velthouse, B. A. (1990). Cognitive elements of empowerment: An "interpretive" model of intrinsic task motivation. Academy of Management Review, 15, 666-681.

Thompson, J. A. (2005). Proactive personality and job performance: A social capital perspective. Journal of Applied Psychology, 90(5), 1011-1017.

Tierney, P., Farmer, S. M., \&Graen, G. B. (1999). An examination of leadership and employee creativity: The relevance of traits and relationships. Personnel Psychology, 52(3), 591-620.

Tymon,W. G., Jr. (1988). An empirical investigation of a cognitive model of empowerment (Unpublished doctoral dissertation). Temple University, Philadelphia.

Van de Ven. A. H. (1986). Central problems in the management of innovation. Management Science, 32, 590-607.

Van der Vegt, G. S., \& Janssen, O. (2003). Joint impact of interdependence and group diversity on innovation. Journal of Management, 29(5), 729-751.

VandeWalle, D., \& Cummings, L. L. (1997). A test of the influence of goal orientation on the feedback-seeking process. Journal of Applied Psychology, 82(3), 390-400.

Vinarski-Peretz, H., \&Carmeli, A. (2011). Linking care felt to engagement in innovative behaviors in the workplace: The mediating role of psychological conditions. Psychology of Aesthetics, Creativity, and the Arts, 5(1), 43-53.

Wayne, S. J., Shore, L. M., \&Liden, R. C. (1997). Perceived organizational support and leader-member exchange: A social exchange perspective. Academy of Management Journal, 40(1), 82-111.

West, M. A. (1989). Innovation amongst health care professionals. Social Behavior, 4, 173-184.

West, M. A., \& Farr, J. L. (1989). Innovation at work: psychological perspectives. Social Behaviour, 4, 15-30.

Williams, L. J., \& Anderson, S. E. (1991). Job satisfaction and organizational commitment as predictors of organizational citizenship and in-role behaviors. Journal of Management, 17(3), 601-617.

Yang, F., \& Chau, R. (2016). Proactive personality and career success. Journal of Managerial Psychology, 31(2), 467-482.

Yıldız, B., \&Yıldız, H. (2015). The effect of servant leadership on psychological ownership: the moderator role of perceived organizational support. Journal of Global Strategic Management, 9(2), 65-77.

Yıldız, B., Erat, S., Alpkan, L., Yıldız, H., \&Sezen, B. (2015). Drivers of innovative constructive deviance: A moderated mediation analysis. Procedia-Social \&Behavioral Sciences, 195, 1407-1416.

Yulan, H. A. N., Min, W., \&Linping, D. (2014). Role conflict and the buffering effect of proactive personality among middle managers. Social Behavior \& Personality: An International Journal, 42(3), 473-486.

Zhang, X., \&Bartol, K. M. (2010). Linking empowering leadership and employee creativity: The influence of psychological empowerment, intrinsic motivation, and creative process engagement. Academy of Management Journal, 53(1), 107-128.

Zimmerman, M. A. (1995). Psychological empowerment: issues and illustrations. American Journal of Community Psychology, 23(5), 581-599.

Zimmerman, M. A., \& Rappaport, J. (1988). Citizen participation, perceived control, and psychological empowerment. American Journal of Community Psychology, 16(5), 725-750. 